“Transfer” XV: 1-2 (2020), pp. 312-337. ISSN: 1886-554

\title{
TRADUCCIÓN AUDIOVISUAL Y PERSPECTIVA DE GÉNERO. A PROPÓSITO DEL TRATAMIENTO DE LA VIOLENCIA VERBAL EN EL DOBLAJE"
}

Laura Carlucci (ORCID: 0000-0001-9986-6522) Universidad de Granada

\footnotetext{
"Una es más auténtica cuanto más se parece a lo que ha soñado de sí misma" Antonia San Juan (Todo sobre mi madre)
}

\section{Introducción}

El presente trabajo parte de la concepción del producto audiovisual como un potente fenómeno social de denuncia de problemáticas sociales, entre ellas la desigualdad, la violencia de género, el racismo y la marginación. En esta tesitura y en relación con la violencia machista y la lucha por la igualdad de género, en los últimos veinte años en España han visto la luz películas tan comprometidas como Solas (1999), Celos (1999), Juana la Loca (2001), Solo mía (2001), Te doy mis ojos (2003) o el drama histórico Ágora (2009), entre otros.

Como aclararemos a continuación, hemos elegido la película de Icíar Bollaín Te doy mis ojos porque consideramos que es la más representativa y por su gran riqueza en matices expresivos. A lo largo del film el espectador experimenta todas las situaciones propias del maltrato, no tanto físico, pues solo hay una escena explícita de violencia, sino psicológico y emocional, con situaciones típicas como el insulto, la descalificación, la crítica destructora el reiterado incumplimiento de una promesa, solo por citar las más evidentes. Todos estos "hábitos normalizados" en una si-

Este trabajo se ha realizado dentro del marco del proyecto "OPERA. Acceso al ocio y a la cultura. Plataforma de difusión y evaluación de recursos audiovisuales accesibles / Access to leisure and culture. Dissemination and assessment of audio visual accessible resources". Code: FFI2015-65934-R 
“Transfer” XV: 1-2 (2020), pp. 312-337. ISSN: 1886-554

tuación de violencia de género van acompañados por manifestaciones de violencia verbal de diferente intensidad, que nos abren paso hacia nuestro análisis sobre el lenguaje malsonante hacia las mujeres en el guion original español y en la versión doblada al italiano. Por lo tanto, emprendemos un estudio mediante el cual evaluamos los insultos desde un punto de vista social y, posteriormente, lingüístico, sometiendo la película a un análisis traductológico que nos permitirá estudiar la presencia de palabras obscenas y lenguaje soez en ambas versiones, para reflexionar sobre los aspectos más relevantes relativos a las estrategias de traducción utilizadas.

\section{Traducción audiovisual y doblaje}

En los últimos años, los medios audiovisuales se han convertido en una parte fundamental de la comunicación, ya que transmiten grandes volúmenes de información, conocimientos, sensaciones, emociones, etc. Una consecuencia de ello es el creciente aumento de la traducción audiovisual (TAV), entendida esta como el conjunto de prácticas traductoras "que se implementan en los medios audiovisuales a la hora de trasvasar un mensaje de una lengua a otra, en un formato en el que hay una interacción semiótica entre el sonido y las imágenes" (Díaz Cintas 2007: 18).

El doblaje es una de las modalidades de la traducción audiovisual (TAV). Según el sistema de traducción del producto audiovisual, podemos distinguir entre diferentes modalidades de traducción: doblaje, subtitulado, voice-over, half-dubbing, narración y traducción simultánea, entre otros (Mayoral 2003). A todas ellas hay que añadirles modalidades de TAV más recientes, como la localización de videojuegos y la supertitulación para el teatro y la ópera, junto a otras se han ido configurando en los últimos años y que entran dentro de la traducción audiovisual accesible para personas con discapacidad sensorial: el subtitulado para sordos o personas con discapacidad auditiva y la audiodescripción para usuarios con discapacidad visual. En estos dos últimos casos estaríamos hablando de una traducción de tipo intralingüístico. 
“Transfer” XV: 1-2 (2020), pp. 312-337. ISSN: 1886-554

Nuestra decisión de analizar la versión doblada de la película Te doy mis ojos, por lo tanto una traducción interlingüística, se debe principalmente a la importancia que se le da en Italia al doblaje, a pesar de la tendencia creciente de ver películas y series en versión original subtitulada. Como es sabido, en el doblaje de un producto audiovisual "se sustituye el texto oral original por otro texto oral en otra lengua" (Hurtado Albir 2001: 78). Por su parte, Frederic Chaume completa esta definición añadiendo que el doblaje es "la traducción y ajuste de un guion de un texto audiovisual y la posterior interpretación de esta traducción por parte de los actores, bajo la dirección del director de doblaje y los consejos del asesor lingüístico, cuando esta figura existe" (Chaume 2004: 32).

\section{La película}

Como hemos tenido ocasión de señalar anteriormente, dentro de los géneros cinematográficos el cine social se emplea como instrumento eficaz de denuncia y condena de determinados problemas relacionados con la violencia de género. La elección de utilizar la película Te doy mis ojos como punto de partida para este trabajo sobre los rasgos lingüísticos del maltrato y la violencia verbal en la versión doblada para el público italiano viene determinada, en primer lugar, porque es la única película que está dirigida -magistralmente- por una mujer, la directora, escritora y actriz Icíar Bollaín, y eso hace que se convierta en un film de mujeres, hecho por mujeres y para mujeres. Personalmente, creemos que una película sobre malos tratos dirigida por una mujer transmite una sensibilidad especial, diferente. El guion de la película, escrito a cuatro manos por Icíar Bollaín y Alicia Luna, es absolutamente realista, sin eufemismos ni tapujos, tiene un discurso proprio y una voz dura y conmovedora a la vez que se eleva para denunciar y condenar la invisibilidad de la violencia doméstica.

En este sentido, Te doy mis ojos tal vez sea la película que más visibilidad da a la lacra de la violencia de género en todas sus 
“Transfer” XV: 1-2 (2020), pp. 312-337. ISSN: 1886-554

manifestaciones: violencia física, acoso y maltrato psicológico, y una de las pocas que conocemos que intenta entender, sin por ello justificar, la actitud del maltratador. De hecho, gracias a la interpretación extraordinaria de sus protagonistas, Pilar y Antonio, alias Laia Marull y Luis Tosar, podemos extraer no solo el perfil de la víctima, sino también el del maltratador, tan importante para nuestro análisis, pues las características que matizan su perfil se asocian a adjetivos como: agresivo, posesivo, celoso, irascible, cobarde, violento o bruto, que justifican la presencia de una violencia verbal y el uso de un lenguaje obsceno y soez. Por último, pero no por eso menos importante, esta película sobrecogedora ha sido una de las más galardonadas por la crítica cinematográfica, siendo ganadora de 7 Premios Goya: mejor película, mejor director, mejor actor principal (Luis Tosar), mejor actriz principal (Laia Marull), mejor actriz de reparto (Candela Peña), mejor guion original y mejor sonido.

La trama de la película es muy conocida y no necesitamos extendernos demasiado sobre ella. La historia se desarrolla en Toledo, una ciudad llena de arte y belleza. En la primera escena Pilar (Laia Marull), después de sufrir el enésimo episodio de maltrato por parte de su marido Antonio, interpretado por un inmenso Luis Tosar, abandona su casa en plena noche, asustada y en zapatillas, llevando consigo a su hijo de ocho años. Busca refugio en casa de su hermana Ana (Candela Peña), y durante el tiempo que se queda en su casa Pilar empieza una nueva vida, encuentra trabajo en una iglesia vendiendo entradas, conoce a otras mujeres y empieza a salir con ellas. Antonio no tarda en ir a buscarla, le envía flores y le regala unos pendientes, le promete que va a cambiar y empieza a ir a terapia para aprender a controlar su ira, sus celos y su comportamiento agresivo. Finalmente logra convencer a Pilar para que vuelva a casa, ella sigue estando enamorada, no ha perdido la esperanza de que su marido cambie y le da una segunda oportunidad. Se siente feliz porque su nuevo trabajo en el museo comentando cuadros durante las visitas guiadas le está dando un nuevo sentido a su vida. Sin embargo, acoso y malos tratos no tardarán en volver a la vida de Pilar, aunque después de cada agresión física o psicológica Antonio se 
“Transfer” XV: 1-2 (2020), pp. 312-337. ISSN: 1886-554

arrepiente, le pide perdón y le promete que nunca más va a volver a pasar. Después del último, terrible episodio de violencia y humillación, Pilar decide marcharse para siempre. Las amigas y compañeras de trabajo de Pilar la acompañan a su casa para recoger sus cosas, delante de la mirada atónita de Antonio. En la última escena Antonio mira a través de la ventana cómo su mujer se aleja: es el final de ese vínculo de dependencia emocional mutuo que ha marcado toda su vida en común. El espectador es testigo de la desgarradora experiencia de Pilar, al tiempo que la evolución de Antonio, cuyo intento de abandonar su comportamiento agresivo y posesivo fracasa y, por lo tanto, desaparece también la posibilidad de recuperar la relación de pareja. Según Lifante, la película tiene tres protagonistas muy claros: el maltratador (Antonio), la víctima (Pilar) y la relación de amor idealizado y a la vez destructivo que se establece entre los dos (Lifante 2012: 2).

Antes de ocuparnos de la violencia verbal, que se manifiesta a través del lenguaje obsceno, ofensivo y malsonante, y analizar de manera contrastiva los diálogos del guión original español y su versión doblada al italiano, creemos conveniente definir brevemente qué rol social desempeñan los personajes masculinos y femeninos de la película.

\subsection{Personajes femeninos}

Cada uno de los personajes femeninos de Te doy mis ojos tiene una diferente respuesta emocional a los malos tratos. Pilar es la víctima, es ama de casa, vive asustada, sumisa, controlada y amenazada por su marido y, sin embargo, es incapaz de alejarse de él. Cuando lo hace, Antonio reconoce su culpa, promete cambiar, se apunta a terapia para controlar su cólera y la manipulación afectiva que ejerce sobre la mujer hace que Pilar abandone la idea de marcharse, convencida de que las cosas cambiarán. La reconciliación conlleva un furtivo encuentro sexual en el piso de Ana; se trata de una escena muy erótica en la que queda patente que la relación de dependencia víctima-maltratador se estrecha nuevamente, ya que Pilar se entrega a Antonio hasta el punto de 
“Transfer” XV: 1-2 (2020), pp. 312-337. ISSN: 1886-554

ofrecerle todo su ser: (Antonio: -"Lo quiero todo". Pilar: - "Ya lo tienes"). Se trata de la famosa secuencia que da el título a la película.

Otro personaje femenino es Aurora, la madre de Pilar y Ana, interpretada por Rosa María Sardá. Ella transmite y perpetúa conscientemente los estereotipos de género, herencia de una mentalidad machista, que funciona según un sistema de dominosumisión legitimado socialmente dentro del patriarcado. Aurora encarna el estereotipo femenino según el cual las mujeres han de ser madres y esposas (“¿Cómo os vais a casar, como dios manda o de cualquier manera?"), cuidar del hogar y de sus hijos, ser dóciles, obedientes y sensibles. Jamás menciona el infierno en el que vive Pilar, como si no fuera real, y sigue justificando y consintiendo la misma forma de maltrato que posiblemente vivió ella en su propio matrimonio. Su idea de pareja se hace patente en la escena de la azotea, cuando le dice a Pilar que debe volver con su marido: "Tú, lo que tendrías que hacer es arreglarte con Antonio y volver a tu casa", porque según ella "una mujer nunca está mejor sola". Aún más representativo es el momento en que la madre le enseña a Ana el vestido de novia de Pilar, para que se lo ponga ella: "ya que no te casas como Dios manda, por lo menos que tengas unas fotos bonitas". Aurora insiste en recordar lo feliz que estaba Pilar el día de su boda, "con esa carita de ilusión", mientras que Ana se enfurece pensando en el infierno en el que vive su hermana: “¡Mamá! ¡Estoy hablando de que tiene varias tendinitis, desgarros musculares, pérdida de visión de un ojo! ¡Ese hijo de la gran puta le ha desplazado el riñón de una patada!" La madre le ordena a Ana que se calle, y en un arrebato de desesperación Pilar le quita de las manos el vestido y lo arroja a la calle. La escena de la azotea es representativa de cómo, según apunta acertadamente Jaimes Hernández, el personaje de la madre representa la normalización social del maltrato (2016: 172).

Ana es la antítesis de Pilar y Aurora. Es fuerte, lleva una vida independiente junto a su pareja escocesa, quiere proteger a su hermana pero no sabe cómo, porque no logra entender su comportamiento, no entiende su silencio, su amor por él y tampo- 
“Transfer” XV: 1-2 (2020), pp. 312-337. ISSN: 1886-554

co que ella siga aguantando esa situación. Además, no le perdona a su madre que evite ver lo que le pasa a su hermana, quitándole importancia al problema.

Por último, destacamos las cuatro nuevas amigas de Pilar (Rosa, Lola, Raquel y Carmen); son mujeres económica y emocionalmente independientes que viven sus relaciones de pareja de forma constructiva. Tienen un papel importante en la evolución de Pilar, le proporcionarán trabajo, la ayudarán a socializar y a salir más y, sobre todo, al final de la película, la acompañarán a casa y le ayudarán a recoger sus cosas, protegiéndola de Antonio.

\subsection{Personajes masculinos}

Todos los personajes masculinos, exceptuando al novio de Ana, encarnan la mentalidad típica de una sociedad patriarcal, donde la mujer es considerada un objeto propiedad del hombre y se ve relegada al ámbito doméstico. Antonio, al igual que los hombres que acuden a la terapia de grupo, ha construido su relación de pareja sobre una base de posesión y dominación.

La escena de los hombres que acuden a la terapia de grupo junto a Antonio es aterradora y demuestra cómo exista una mentalidad machista todavía difícil de arraigar. Durante las sesiones de terapia los hombres hablan entre ellos y justifican constantemente la reacción violenta hacia sus mujeres: "las mujeres tiene muchas maneras de volverte loco perdido" dice uno de ellos, y los demás asienten; otro marido define a su mujer como "histérica perdida, que no da pie con bola". Sobra decir que la conversación entre ellos está repleta de palabras descalificadoras. Generalmente le dan poca o ninguna importancia a los episodios de violencia e insultos, e incluso los consideran como algo normal ("algunas veces le he dado un empujón, pero eso no es pegar"). Están convencidos de que solo por trabajar y llevar a casa el dinero tienen derecho a exigir de sus mujeres obediencia, dedicación absoluta a las tareas del hogar y obligación a satisfacer sus deseos sexuales, tal y como afirma convencido uno de ellos: "Llego a casa cansado, peleando con la vida, he estado trabajando para tu casa, tu mujer, para todo, ¡cojones! [...] buscando cariño... buscando sexo, vamos Que creo que eso es darse a la pareja. Y me 
“Transfer” XV: 1-2 (2020), pp. 312-337. ISSN: 1886-554

rehúye. Yo a lo mejor la despierto, y la hija puta [...] y a ti te entra una cosa... y le metes".

A través del análisis de algunos fragmentos de diálogos podemos observar que ninguno de ellos, a excepción de un paciente, se cuestiona la gravedad de sus actos, sino que incluso los justifica: "mi mujer me provoca precisamente para que yo la pegue".

Otro personaje secundario que encarna los rasgos típicos del hombre machista es el policía. Tras la última humillación, Pilar decide denunciar a Antonio. La breve secuencia en Comisaría y la conversación con el policía que la atiende es reveladora de hasta qué punto la sociedad tolera el maltrato. De hecho, desde el primer momento el policía parece no tomarla en serio. No entiende porqué quiere denunciar a Antonio si ella afirma que él no le ha pegado. Merece la pena transcribir este breve diálogo:

Policía: Dígame ¿Dónde la agredió?

Pilar: No tengo nada por fuera. Es por dentro.

Policía: [...] Dice que no la agredió físicamente. ¿La insultó? ¿La amenazó verbalmente?

Pilar: Lo ha roto todo.

Policía: ¿Ha roto objetos suyos personales?

La figura de John, el novio escocés de Ana, representa la antítesis de Antonio y de los hombres de la terapia. En contraste con la mentalidad de los demás hombres de la película, es atento, amable, colabora en las tareas domésticas, apoya a Ana en los preparativos de su boda, dando una imagen de masculinidad completamente alejada de la de Antonio. Es el único prototipo de masculinidad distinta de la tradicional, de ahí que su papel no es indicativo para nuestro estudio, por lo que no lo incluiremos entre los personajes masculinos analizados. 
“Transfer” XV: 1-2 (2020), pp. 312-337. ISSN: 1886-554

\section{Metodología del estudio}

En cuanto a la metodología que hemos utilizado, tras visionar la película tanto en su versión original en español como en la versión doblada al italiano, hemos localizado los aspectos relacionados con el lenguaje obsceno, soez y discriminatorio utilizado por los hombres en el film. En este sentido, nuestra atención se ha dirigido no solo a las amenazas e insultos directos de Antonio hacia Pilar, sino también a los insultos indirectos, es decir, la forma en la que los personajes masculinos de la película, tanto Antonio como los demás maridos/novios que acuden a la terapia de grupo, hablan de sus mujeres y opinan sobre ellas.

También consideramos insultos indirectos aquellos comportamientos que llegan a herir a la protagonista femenina sin necesidad de que exista expresión verbal, como los gestos, la mirada y la expresión de la cara del maltratador, aspectos todos ellos que refuerzan el mensaje vejatorio en las escenas de violencia de la película.

Bollaín acerca al espectador al personaje de Pilar de tal manera que consigue transmitirle el mismo miedo que ella está teniendo, gracias a recursos como los movimientos de la cámara, en un juego constante de picados y contrapicados, así como el lenguaje no verbal y paraverbal, la música y los sonidos diegéticos y extradiegéticos. En definitiva, la directora opta por sugerir más que mostrar, de hecho, sólo hay una escena de violencia explícita. En las demás situaciones, el uso del silencio en los canales sonoro y visual se convierte en una herramienta muy eficaz para relatar el drama que vive Pilar. La pregnancia semántica del silencio, que consideramos el cuarto gran protagonista de esta película, se percibe a través de los numerosos cortes y pausas, cuya función es la de representar los sentimientos de los protagonistas, las preguntas que quedan sin contestar o, incluso, las conversaciones que nunca se iniciaron (Carlucci \& Rodríguez 2014). Son todos aspectos que hay que tener en cuenta a la hora de crear la versión doblada. Tampoco hay que olvidar que determinadas expresiones del rostro tienden a tener un significado universal, por lo que es importante que el lenguaje verbal que se utiliza en la versión 
“Transfer” XV: 1-2 (2020), pp. 312-337. ISSN: 1886-554

doblada acompañe de forma correcta y con la misma intensidad expresiva el gesto, la postura o la mirada del personaje.

Por lo tanto, el uso de una modalidad u otra de traducción dependerá de la situación en la que se encuentren los personajes, pero es indudable que el complicado conjunto de señales no verbales (prosódicas, paralingüísticas y proxémicas) enfatiza el acto de habla y es determinante en la traducción, a la hora de optar por la intensidad del término elegido en la lengua meta. En otras palabras, habrá que tener en cuenta la multisemioticidad del producto audiovisual, así como el aspecto pragmático de la traducción, para verificar de qué manera el lenguaje obsceno, violento e insultante del guion original español encaja en la versión doblada al italiano.

En relación con el procedimiento que hemos adoptado, el estudio contrastivo se elaborará en formato de ficha en la que se reflejan los siguientes apartados: el contexto, es decir, una síntesis de la escena para poder contextualizar el diálogo, el nombre del personaje que habla, la trascripción del diálogo en español (VOE) y la correspondiente traducción italiana para el doblaje. El cotejo de sendos diálogos nos permitirá registrar las modalidades de traducción empleadas para el doblaje, siguiendo la taxonomía propuesta por Martí (2006); de esta forma, nos resultará más fácil comparar ambas versiones y analizar si se conserva en todos los casos el contenido denigratorio, o bien si se registra una tendencia a la atenuación del lenguaje soez.

\section{Tratamiento de la violencia verbal}

Como hemos podido observar en los apartados anteriores de este trabajo, el maltrato y el control sobre la mujer no se manifiestan solo a través de los comportamientos, sino también a través del lenguaje, que discrimina, insulta y humilla a la víctima. Siguiendo la definición de Haverkate, el insulto es un "estado psicológico del hablante, causado por un cambio en el mundo que le atañe al interlocutor o a él mismo (1994: 80). 
“Transfer” XV: 1-2 (2020), pp. 312-337. ISSN: 1886-554

Siguiendo las categorizaciones de Ángeles Álvarez (en Fernández Romero 2012: 114) cabe destacar que existe una forma de violencia verbal que ejerce el maltratador sobre su víctima y que implica comentarios degradantes, insultos, descalificaciones, frases humillantes sobre la falta de atracción física, etc. Por otro lado, la violencia de género se manifiesta también a través de una violencia de tipo emocional, que tiene la finalidad de minar la autoestima de la víctima, e incluye acciones como la destrucción de objetos que tienen algún valor sentimental (es el caso del libro de arte que Antonio destroza delante de Pilar), la insistencia en considerar a la víctima incompetente o inútil ("estás hablando de gilipolleces todo el puto día”, refiriéndose al trabajo de Pilar en el museo), ignorar su presencia o manifestar celos y sospechas continuas (¿por qué no has cogido el teléfono?, ¿con quién ha comido?, ¿y con quién más?).

Con respecto a las posibles estrategias de atenuación de los términos vulgares y malsonantes de la VOE, en el caso en que la palabra soez no se mantenga, seguiremos la clasificación de García Aguiar \& García Jiménez (2013: 141-142), que se centran en procedimientos de tipo lexical, como el eufemismo, la omisión o la reducción del contenido y la elipsis, o bien de tipo gramatical, como el circunloquio. En Antonio el lenguaje no verbal resulta igual de agresivo que las palabras: gritos y miradas desafiantes, expresión facial de ira o aversión hacia su mujer, invadir el espacio físico de la pareja para intimidarla, como ocurre en la escena en que los dos hablan a través del ventanuco de la puerta y él introduce los brazos a través del postigo para tocarle la cara. Pilar tiembla de miedo, Antonio intenta ser amable, controla sus gestos y su tono de voz, mete las manos a través del pequeño ventanuco y la acaricia, pero al ver que ella sigue sin querer abrir la puerta vuelve a elevar el tono de voz: “Pilar, coño, abre la puerta, joder!”

Por otro lado, tal y como apuntan Franco Aixelá y Abio Villarig, el traductor recurre a la censura cuando "el original presenta visiones del mundo que desbordan la tolerancia del polo de recepción" (2009: 111) La consiguiente censura, según estos autores, se presentará en forma de atenuación, donde la omisión se convierte en la estrategia más común. Por otro lado, refiriéndose a 
“Transfer” XV: 1-2 (2020), pp. 312-337. ISSN: 1886-554

la técnica de reducción en la traducción audiovisual, Mayoral la define como una técnica de "alteración de la extensión" del texto que, a diferencia de la ampliación, tiene signo negativo. Así pues, considera la omisión como "un caso particular de reducción" (Mayoral 2003: 108), más concretamente, una reducción a través de un recorte del significado. En relación con la disminución del número de insultos en el doblaje de una película, Soler Pardo señala una serie de factores que justificarían su eliminación, entre ellos la sincronización labial y la falta de espacio o tiempo, dado que "al tener que eliminar, para que coincidan los textos, algún tipo de información se decide prescindir la que no aporta un significado importante a la oración, los tacos" (Soler Pardo 2014: 136). Otro motivo de eliminación de palabras ofensivas o soeces respondería a una forma de censura con fines comerciales (en el caso de la distribuidora) o bien de autocensura (por parte del traductor y/o adaptador) por considerarlas moralmente inadecuadas.

Tras esta breve premisa, veamos a continuación qué tipo de insultos, palabras malsonantes y expresiones con una clara intención hiriente aparecen en el guion original de Te doy mis ojos, y qué tratamiento reciben en el doblaje al italiano. Para ello, seleccionaremos las diez escenas más representativas de la película, acompañadas por los comentarios correspondientes. Resaltamos en cursiva los términos o expresiones más relevantes dentro del lenguaje malsonante en ambas lenguas.

Escena 1

\begin{tabular}{|l|l|}
\hline CONTEXTO & $\begin{array}{l}\text { Pilar se ha marchado. Por la mañana Ana va a su } \\
\text { casa para recoger algunos objetos, ropa y los } \\
\text { libros del niño. Llega Antonio }\end{array}$ \\
\hline VOE & $\begin{array}{l}\text { Antonio: } \\
\text { ¿Y tú qué coño haces aquí? } \\
\text { Márchate. iFuera de aquí! } \\
\text { Anda, dile a Pilar que se deje de hostias y que } \\
\text { venga a casa que hablamos }\end{array}$ \\
\hline DOBLAJE & $\begin{array}{l}\text { Antonio: } \\
\text { E tu che cazzo ci fai qui? }\end{array}$ \\
\hline
\end{tabular}


“Transfer” XV: 1-2 (2020), pp. 312-337. ISSN: 1886-554

\begin{tabular}{|l|l|}
\hline & $\begin{array}{l}\text { Vattene via! } \\
\text { Dille che la smetta di fare la vittima e venga a } \\
\text { parlare con me [...] }\end{array}$ \\
\hline
\end{tabular}

En esta primera escena Antonio le reprocha a Ana la actitud de víctima de su hermana. La sorpresa de Antonio al encontrarse a su cuñada en casa se expresa, en el caso de la VOE, con el empleo del imperativo directo "márchate" (italiano vattene), que subraya su superioridad y recalca la relación jerárquica entre él y Ana. En ambas versiones se opta por utilizar una exclamación de rigor (qué haces aquí/cosa ci fai qui?), reforzada por un taco, para que la frase adquiera una connotación vulgar y grosera que denote enfado ( $E$ tu che cazzo ci fai qui?) La técnica de traducción seguida es la creación discursiva, puesto que se crea una equivalencia funcional.

Escena 2

\begin{tabular}{|l|l|}
\hline CONTEXTO & $\begin{array}{l}\text { Antonio busca a Pilar en casa de la hermana. Se } \\
\text { hablan a través de un ventanuco de la puerta. }\end{array}$ \\
\hline VOE & $\begin{array}{l}\text { Antonio: } \\
\text { No puedes hacerme esto. Me cago en la puta, me } \\
\text { estás jodiendo, Pilar [...] } \\
\text { Venga déjate de tonterías y vamos a tomar café. } \\
\text { iPilar coño abre la puerta, joder! } \\
\text { ¿Qué pasa? ¿Ya no me quieres? [...] Canija, yo } \\
\text { sin ti no puedo vivir. } \\
\text { Mírame Pilar, abre la puerta, abre la puerta. } \\
\text { [GRITA] iJoder abre la puerta! }\end{array}$ \\
\hline DOBLAJE & $\begin{array}{l}\text { Antonio: } \\
\text { Non puoi farmi questo. Mi hai mollato senza } \\
\text { dirmi una parola, senza dirmi un cazzo! } \\
\text { Piantala con le stronzate, andiamo al bar e par- } \\
\text { liamo. Pilar, cazzo apri la porta [...] } \\
\text { Su, chiquita. Che c'è. Non mi ami più? [...] Chi- } \\
\text { quita senza di te non posso vivere. } \\
\text { Pilar guardami, dai apri la porta. [GRIDA] Pilar, } \\
\text { cazzo, apri la porta! }\end{array}$ \\
\hline
\end{tabular}


“Transfer” XV: 1-2 (2020), pp. 312-337. ISSN: 1886-554

Esta escena permite observar cómo la aparente dulzura de Antonio se convierte en rabia cuando ve que ella no le abre la puerta. En este caso, las palabras "coño" y "joder" actúan como interjecciones, al igual que su correspondiente italiano "cazzo", por lo que se mantiene el sentido del original; la repetición de las palabras malsonantes en ambas lenguas tiene la función de intensificador enfático del discurso. Además, en el caso del doblaje, la reduplicación expresiva del italiano realza el tono colérico de Antonio. Lo mismo ocurre con la decisión de traducir "tonterías" por stronzate. El término italiano tiene una connotación muy vulgar, frente al español "tonterías" (sciocchezze) aunque se suele asociar también a la estupidez, al modo de pensar o actuar de un tonto. Teniendo en cuenta el enfado de Antonio por haber sido abandonado por Pilar, consideramos acertada la propuesta de la versión italiana. Cabe destacar el término "canija”, con el que Antonio se refiere a Pilar, es aparentemente cariñoso, pero esconde el menosprecio de su aspecto físico. El doblaje opta por un diminutivo en español inteligible para un espectador italiano: chiquita.

Escena 3

\begin{tabular}{|l|l|}
\hline CONTEXTO & $\begin{array}{l}\text { Pilar y Ana por la calle. Ana le dice que se quede } \\
\text { con ella y busque trabajo }\end{array}$ \\
\hline VOE & $\begin{array}{l}\text { Pilar: ¿Y de qué vivo, del aire? Hace siglos que no } \\
\text { trabajo, Ana. Y Antonio ¿qué va a hacer? } \\
\text { Ana: iA Antonio que le den por culo, Pilar! }\end{array}$ \\
\hline DOBLAJE & $\begin{array}{l}\text { Pilar: E di che vivo, di aria? Sono secoli che non } \\
\text { lavoro, Ana. E Antonio che farà? } \\
\text { Ana: Che vada affanculo. }\end{array}$ \\
\hline
\end{tabular}

En esta escena inicial observamos cómo el lenguaje vulgar se mantiene a través de una traducción literal, la expresión coin- 
“Transfer” XV: 1-2 (2020), pp. 312-337. ISSN: 1886-554

cide en ambos idiomas y en el doblaje se mantiene el mismo campo semántico que en la VOE. La elección de utilizar un eufemismo para suavizar la expresión italiana (por ejemplo che vada al diavolo, che vada a quel paese), se desaconsejaría en este caso, conociendo la animadversión de Ana hacia su cuñado.

\section{Escena 4}

\begin{tabular}{|l|l|}
\hline CONTEXTO & $\begin{array}{l}\text { Antonio ha ido a ver a su hijo Juan. Juegan al } \\
\text { fútbol }\end{array}$ \\
\hline VOE & $\begin{array}{l}\text { Antonio: ¿Y tu madre qué coño hace todo el día? } \\
\text { Juan: Trabaja } \\
\text { Antonio: ¿Qué significa que trabaja? ¿Qué te ha } \\
\text { dicho tu madre? ¿Qué me vais a dejar aquí solo } \\
\text { para siempre? [...] ¿Sale con alguien tu madre? }\end{array}$ \\
\hline DOBLAJE & $\begin{array}{l}\text { Antonio: } \\
\text { Tua madre cosa fa tutto il giorno? } \\
\text { Juan: Lavora } \\
\text { Antonio: Che significa lavora? [...] Che ti ha detto } \\
\text { tua madre? Che mi lascerete solo per sempre? [...] } \\
\text { Che ti ha detto? Che ti ha detto? Esce con qual- } \\
\text { cuno tua madre? }\end{array}$ \\
\hline
\end{tabular}

En la primera frase de este fragmento se aprecia una omisión, pues la interjección "coño" desaparece en el doblaje, a diferencia de lo que ocurría en la escena 2. La omisión, por lo tanto, no respeta el contenido vulgar de la VOE, que se pierde completamente. Es bastante sorprendente, pues al tratarse de dos palabras de dos sílabas cada una que se usan en un contexto parecido, la pérdida del contenido no se justifica por una restricción técnica, como puede ser la sincronía labial. Hemos incluido la pregunta “¿Qué significa trabaja?” por el tono de menosprecio que usa Antonio, pues su idea de una relación de pareja implica que la mujer sea un ama de casa. 
“Transfer” XV: 1-2 (2020), pp. 312-337. ISSN: 1886-554

Escena 5

\begin{tabular}{|l|l|}
\hline CONTEXTO & $\begin{array}{l}\text { En la azotea están Pilar, Ana y Aurora, que tiene } \\
\text { en mano el vestido de boda de Pilar, para que Ana } \\
\text { se lo pruebe }\end{array}$ \\
\hline VOE & $\begin{array}{l}\text { Ana: ¡Que no, mamá, que no me voy a casar yo } \\
\text { hecha una mamarracha! Perdona, Pilar, mama- } \\
\text { rracha quiere decir que el vestido es precioso, } \\
\text { pero que no es mi rollo. }\end{array}$ \\
\hline DOBLAJE & $\begin{array}{l}\text { Ana: No mamma. Non voglio sposarmi conciata } \\
\text { come un pagliaccio. } \\
\text { Pilar scusa per il pagliaccio. Il vestito è molto } \\
\text { carino ma non è adatto a me. }\end{array}$ \\
\hline
\end{tabular}

En esta escena el personaje que utiliza el término despectivo hacia Pilar es su hermana Ana. Ella está en contra de toda tradición, sin embargo su madre sigue insistiendo para que se pruebe el vestido de novia de Pilar. Para dejar zancada la cuestión, utiliza la palabra mamarracha. El DRAE define "mamarracho" como "persona estrafalaria o ridícula", y advierte que se puede utilizar también como insulto. La palabra pagliaccio en italiano, además de indicar un artista de circo que hace reír y viste de forma extravagante, al igual que el español "payaso", también se puede usar con un sentido más despectivo, por lo que, en esta ocasión, se han mantenido el mismo matiz y campo semántico del término español, siempre teniendo en cuenta que se trata de sinónimos parciales, cuyo uso depende de un contesto o situación determinados.

Escena 6

\begin{tabular}{|l|l|}
\hline CONTEXTO & $\begin{array}{l}\text { Siguen en la azotea. La madre acaba de decirle a } \\
\text { Pilar que debería volver con su marido }\end{array}$ \\
\hline VOE & $\begin{array}{l}\text { Ana: iUna mierda! Lo que tendría que hacer es } \\
\text { separarse, y pedir una orden de alejamiento }[. . .] \\
\text { iEse hijo de la gran puta le ha desplazado el riñón }\end{array}$ \\
\hline
\end{tabular}


“Transfer” XV: 1-2 (2020), pp. 312-337. ISSN: 1886-554

\begin{tabular}{|l|l|}
\hline & $\begin{array}{l}\text { de una patada! } \\
\text { Aurora: Deja tranquila a tu hermana }\end{array}$ \\
\hline DOBLAJE & $\begin{array}{l}\text { Ana: Col cavolo! Quello che deve fare è lasciarlo e } \\
\text { chiedere immediatamente la separazione legale. } \\
{[\ldots]} \\
\text { Quel gran figlio di puttana le ha spostato un rene } \\
\text { con un calcio! }\end{array}$ \\
\hline
\end{tabular}

En la traducción para el doblaje de esta escena se han realizado algunos cambios interesantes. En primer lugar, el uso del italiano Col cavolo!, frecuente en exclamaciones y expresiones populares con el significado de "de ninguna manera", "ni por asomo", "ni de coña". Se mantiene el significado a través de una traducción funcional, pero se pierde el lenguaje vulgar del español “iUna mierda!”. Sin embargo, entre "hijo de la gran puta” y gran figlio di puttana se establece una equivalencia total, a través de una traducción literal, con una leve alteración del orden de las palabras. Ambas expresiones comparten el mismo campo semántico.

A pesar de no ser una forma de manifestación de la violencia verbal, hemos querido incluir en este diálogo el concepto jurídico de "orden de alejamiento", porque consideramos que la traducción italiana separazione legale no es correcta, pues se trata de una traducción funcional, sin embargo, se pierde completamente el concepto de pena privativa de derechos implícita en el término español, que hace referencia a la prohibición de acercamiento o comunicación con la víctima de malos tratos y sus familiares. El concepto jurídico correspondiente en italiano sería ordine restrittivo.

Escena 7

\begin{tabular}{|l|l|}
\hline CONTEXTO & $\begin{array}{l}\text { Terapia de grupo para maltratadores. } \\
\text { Conversación entre los participantes }\end{array}$ \\
\hline VOE & $\begin{array}{l}\text {-Está histérica perdida, no da pie con bola. } \\
\text {-Alguna vez le he dado un empujón, pero eso no } \\
\text { es pegar. }\end{array}$ \\
\hline
\end{tabular}


“Transfer” XV: 1-2 (2020), pp. 312-337. ISSN: 1886-554

\begin{tabular}{|l|l|}
\hline \multirow{7}{*}{ DOBLAJE } & $\begin{array}{l}\text {-Le meto un guantazo y se queda más suave que } \\
\text { un guante } \\
\text {-Es ella la que me provoca. Me provoca preci- } \\
\text { samente para que yo le pegue. }\end{array}$ \\
\hline $\begin{array}{l}\text {-Ė un'isterica pazza. Racconta palle. Ora va a dire } \\
\text { in giro che la picchio. Qualche volta le ho dato } \\
\text { uno spintone, ma questo non è picchiare } \\
\text {-Quando le dò una sberla lei diventa più morbida } \\
\text { di un guanto } \\
\text {-È lei che mi provoca. Lo fa apposta perché io la } \\
\text { picchi. } \\
\text {-Ma lei non ti dava motivi per suonargliele? }\end{array}$ \\
\hline
\end{tabular}

Esta escena es un buen ejemplo de cómo los hombres de la terapia legitiman la violencia doméstica, causada, según ellos, por un comportamiento femenino "equivocado". Todos parecen justificar y compartir los motivos de los malos tratos (la provoca-ción por parte de las mujeres) y el lenguaje ofensivo y denigrante que utilizan para hablar de ellas. Desde el punto de vista semántico, cabe señalar la generalización como técnica de traducción empleada en la palabra italiana sberla (en español: bofetada) una palabra mucho más general y neutra que el español guantazo. La violencia verbal del término español, más afín a la prepotencia propia de unos maltratadores, se pierde completa-mente en el doblaje. El italiano ceffone, o schiaffone, en lugar del eufemismo sberla hubiera sido más acertado en este contexto. En el caso del verbo "pegar", traducido muy acertadamente con suo-nargliele, se ha aplicado la técnica de la particularización, utilizando un término más preciso y concreto que el genérico picchiare (pegar).

Escena 8

\begin{tabular}{|l|l|}
\hline CONTEXTO & $\begin{array}{l}\text { Pilar y Antonio acaban de hacer el amor en casa } \\
\text { de Ana. Lo han vivido de forma muy pasional }\end{array}$ \\
\hline VOE & $\begin{array}{l}\text { ¿Qué quieres ahora, echarte novio? ¿Quieres a un } \\
\text { novio inglés como tu hermana? }\end{array}$ \\
\hline
\end{tabular}


“Transfer” XV: 1-2 (2020), pp. 312-337. ISSN: 1886-554

\begin{tabular}{|l|l|}
\hline DOBLAJE & Antonio: Non è che ti stai cercando qualche altro \\
\hline
\end{tabular}

fidanzato? Vuoi un inglese come tua sorella?

Lo sorprendente de esta escena es que Antonio pronuncia una frase muy hiriente, con la que acusa indirectamente a Pilar de desear acostarse con otro hombre, cuando acaba de hacer el amor con ella. Esta frase sarcástica es otra demostración de la constante lucha interior del protagonista, que se debate entre sentimientos encontrados: por un lado la amabilidad, el cariño, el amor y por otro el desprecio, los celos y la cólera.

Escena 9

\begin{tabular}{|l|l|}
\hline CONTEXTO & $\begin{array}{l}\text { Pilar y Antonio están en la cocina. Él está } \\
\text { enfadado porque ha llegado a casa y ella no } \\
\text { estaba, y tampoco contestaba al teléfono }\end{array}$ \\
\hline VOE & $\begin{array}{l}\text { Antonio: iSe te va la cabeza en tonterías, } \\
\text { cojones! / Solo piensas en gilipolleces /No sabes } \\
\text { hacer dos cosas a la vez }\end{array}$ \\
\hline DOBLAJE & $\begin{array}{l}\text { Antonio: Hai sempre la testa fra le nuvole! / } \\
\text { Pensi solo alle stronzate / Non sai fare due cose } \\
\text { alla volta }\end{array}$ \\
\hline
\end{tabular}

Trascribimos solo algunas de las frases descalificativas que Antonio pronuncia para ridiculizar a Pilar y minar su autoestima. Se trata de un verdadero acoso verbal por parte de él, insistente y repetitivo, mientras Pilar recibe otra agresión física y Antonio coge el sacacorchos y se hace un corte en el antebrazo, disimulando un intento de suicidio. Las tres frases desempeñan una función descalificadora ("no sabes hacer dos cosas a la vez, solo piensas en gilipolleces”...), acorde con los mecanismos clásicos de maltrato. Con respecto a la elección del equivalente semántico, la traducción de "gilipolleces" por stronzate es una adaptación del término original, por lo que se mantiene el contenido y el registro vulgar. La interjección "cojones", sin embargo, se omite en el do- 
“Transfer” XV: 1-2 (2020), pp. 312-337. ISSN: 1886-554

blaje. Tal y como comentamos en la Escena, 2 en relación con la palabra malsonante cazzo, se trata de interjecciones vulgares que denotan disgusto o enfado, por lo que tiene una carga semántica que se debería mantener en fase de traducción.

Escena 10

\begin{tabular}{|c|c|}
\hline CONTEXTO & $\begin{array}{l}\text { Se trata de la agresión en el salón y el balcón. La } \\
\text { escena más aterradora y escalofriante de la } \\
\text { película (se adjuntan solo las frases/expresiones } \\
\text { más relevantes y llamativas) }\end{array}$ \\
\hline VOE & $\begin{array}{l}\text { Antonio: ¡Mírame cuando te hablo! ¡Vuélvete! } \\
\text { ¡Vaya pinta! } \\
\text { Pilar: Quiero estar presentable. } \\
\text { Antonio: Sí, y que te miren, ¿no? [...] Mentirosa. } \\
\text { Eso es lo que te enrolla, ¿eh? Que [...] te miren las } \\
\text { piernas y el culo. ¿A ver cómo hablas de tus } \\
\text { cuadros? [...] A ver la historia esa del Dios que } \\
\text { echa un polvo de puta madre, ¿cómo es eso? [...] } \\
\text { Pilar: Antonio, me están esperando. } \\
\text { Antonio: Uno de estos. A ver, este. El de las } \\
\text { gordas en pelotas. ¿Cómo es esto? ¿Qué hacen? } \\
\text { ¿Esta quién es? La diosa de la menopausia que le } \\
\text { toca el chichi a la diosa de la celulitis. } \\
\text { O sea, ¿que no te gusta este? Pues lo quitamos. Y, } \\
\text { ¿este? Este tampoco. [arrancando las páginas del } \\
\text { libro de arte] } \\
\text { ¿Por qué no lo cuentas? ¿Qué pasa, que no hay } \\
\text { público suficiente para escuchar tus gilipolleces? } \\
\text { [...] Es lo que te enrolla. Te enrolla que te miren, y } \\
\text { que te miren de arriba a abajo, el culo, las tetas } \\
\text { [...]. }\end{array}$ \\
\hline DOBLAJE & 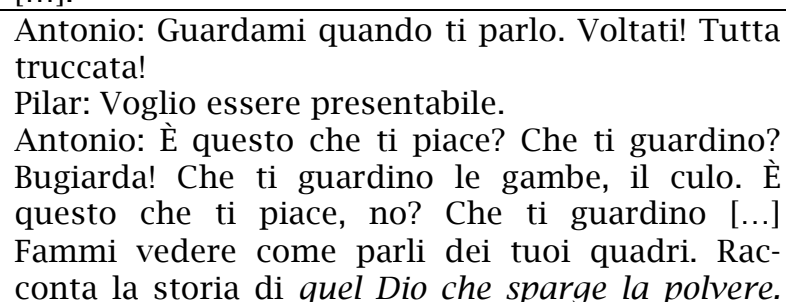 \\
\hline
\end{tabular}


“Transfer” XV: 1-2 (2020), pp. 312-337. ISSN: 1886-554

\begin{tabular}{|l|l|}
\hline Come fa? \\
Pilar: Antonio, mi stanno aspettando- \\
Antonio: Uno di questi. Questo delle grassone \\
nude. Che significa? Questa qui chi è, questa? È la \\
dea della menopausa che palpeggia quella della \\
cellulite. \\
Questo non ti piace? Allora lo buttiamo. E questo? \\
Anche questo? Perché non me lo racconti? Non c'è \\
pubblico sufficiente per raccontare le tue \\
stronzate? No, quello che vuoi è che ti guardino \\
tutta, dall'alto in basso, il culo, le tette e tutto il \\
resto [...]
\end{tabular}

Hemos querido dejar por última la escena 10 por la violencia verbal de la agresión final, aunque el orden cronológico de las secuencias seria invertido: antes la escena 10 y luego la escena 9. Por motivos de espacio hemos tenido que seleccionar fragmentos de diálogo, pues la escena dura alrededor de cinco minutos. Desde un punto de vista general, la mayor parte del diálogo responde a una traducción literal, pues el número de palabras no siempre coinciden y a veces se altera su orden dentro de la frase. Una de las pocas excepciones es la exclamación "¡Vaya pinta!", que pronuncia Antonio cuando ve a Pilar. Demuestra asombro y sorpresa por el vestuario que lleva, el peinado y el maquillaje, mientras que en el doblaje se hace hincapié solamente en el hecho de que está maquillada: Tutta truccata!. Sin embargo, la violencia verbal y la violencia visual son sobrecogedoras y merecen una atención especial. Esta vez la agresión a Pilar es a la vez física, emocional, psicológica, verbal, hasta material y simbólica, como cuando Antonio arranca las páginas de su libro de arte. En esta última escena de agresión Antonio utiliza un lenguaje con fuertes connotaciones sexuales, para humillar y avergonzar aún más a su mujer, y la acusa repitiendo la frase: "Te enrolla que te miren", traducida con el hiperónimo piacere, verbo general y neutro exento de connotaciones. Nos detenemos en dos expresiones empleadas por Antonio, ambas relacionadas con ese mundo del arte que ha conseguido liberar a Pilar de sus ataduras. La 
“Transfer” XV: 1-2 (2020), pp. 312-337. ISSN: 1886-554

primera hace referencia al conocido cuadro de Tiziano: "Dánae recibiendo la lluvia de oro", que representa el mito de Zeus que toma la forma de lluvia dorada para seducir a Dánae y poseerla. Esta información es necesaria para comprender el juego de palabras de Antonio, que le exige a Pilar que le cuente la historia de ese "Dios que echa un polvo de puta madre". En italiano no hay una expresión parecida, pues no se puede utilizar el término polvere en la acepción de mantener relaciones sexuales con alguien, por lo que la expresión española se traduce en su significado literal y no figurado, resultando imposible mantener el juego de palabras: la storia di quel Dio che sparge la polvere. De este modo se pierde completamente el mensaje obsceno del original y hay una pérdida de información importante. El segundo ejemplo de lenguaje obsceno se encuentra en la descripción que hace Antonio de una imagen del libro: "El de las gordas en pelotas. [...] ¿Qué es? ¿La diosa de la menopausia que le toca el chichi a la diosa de la celulitis?". Cabe señalar que la locución adverbial "en pelotas" se traduce por el adjetivo neutro nude. Finalmente, el traductor del doblaje consideraría demasiado obscena la palabra figa para traducirla al español por lo que se utilizó el verbo palpeggiare, que correspondería al español sobar, manosear, toquetear. La técnica de traducción utilizada sería la atenuación del significado, por medio de un eufemismo. La versión para doblaje se quedó así: Questo delle grassone nude. Ė la dea della menopausa che palpeggia quella della cellulite?

\section{Conclusiones}

Creemos que en la película Te doy mis ojos el tema tan dramático y tan común de la violencia de género, que es retratado por su directora de una forma extremadamente real y abrumadora, ha influido en la decisión de mantener lo más posible en la versión doblada la fidelidad al texto original, a pesar de que, en algunos casos, la traducción de insultos y palabras obscenas podría resultar inapropiada para la audiencia italiana. La comparación entre el guion original y la versión doblada pone de manifiesto que 
“Transfer” XV: 1-2 (2020), pp. 312-337. ISSN: 1886-554

el nivel de insultos y el uso de palabras obscenas dirigidas hacia la mujer disminuye ligeramente en italiano, mediante modalidades de traducción como la omisión y la atenuación y el uso de eufemismos, aunque, en términos generales, se observa que la mayoría de ellos se ha mantenido tal cual y no se ha considerado necesario suavizarlos. Es más, en algunas ocasiones se ha observado una intensificación de la traducción del término vulgar, mediante estrategias de repetición. Si partimos de la base de que las palabras malsonantes y los insultos obscenos siempre han de considerarse ofensivos, su eliminación en la versión doblada produciría inevitablemente un cambio en el tono y la finalidad de la película y alteraría el sentido original del mensaje que quiere transmitirnos.

\section{Referencias bibliográficas}

AIXELÁ FRANCO, Javier \& ABIO VILLARIG, Carlos. (2009). "Manipulación ideológica y traducción: atenuación e intensificación moral en la traducción de la novela negra norteamericana al español (1933-2001)”, Hermeneus 1(11): 109-144.

CARLUCCI, Laura \& RODRÍGUEZ DOMÍNGUEZ, Ana (2014). “Amore e violenza: audiodescrizione e linguaggio cinematografico per infrangere le barriere sensoriali e quelle del silenzio". En: CERRATO, Daniele; COLLUFIO, Claudia; COSCO Silvio; MARTÍN CLAVIJO Milagro (eds.). Estupro. Mitos antiguos \& violencia moderna: homenaje a Franca Rame. Sevilla: Arcibel Editores, pp. 64-78.

CHAUME VARELA, Frederic. (2004). Cine y traducción. Madrid: Cátedra.

DÍAZ CINTAS, Jorge. (2007). Traducción audiovisual y accesibilidad. Subtitulación para sordos y audiodescripción para ciegos: nuevas modalidades de Traducción Audiovisual. En: JIMÉNEZ HURTADO, C. (2007) (ed.) Traducción y accesibilidad. Frankfurt a. M.: Peter Lang. 
“Transfer” XV: 1-2 (2020), pp. 312-337. ISSN: 1886-554

FERNÁNDEZ ROMERO, Diana. (2012). Destrucción y reconstrucción de la identidad de mujeres maltratadas: análisis de discursos autobiográficos y de publicidad institucional. Tesis Doctoral. Universidad Complutense de Madrid [en línea]. $<<$ https://eprints.ucm.es/16149/1/T33834.pdf $>>$ [Consulta: 2 de septiembre de 2019].

GARCÍA AGUIAR, Livia \& GARCÍA JIMÉNEZ, Rocío. (2013). "Estrategias de atenuación del lenguaje soez: algunos procedimientos lingüísticos en el doblaje para Hispanoamérica de la película Death Proof". Estudios de Traducción, 3: 135-148.

HAVERKATE, Henk. (1994). La cortesía verbal. Estudio pragmalingüístico. Madrid: Gredos.

HURTADO ALBIR, Amparo. (2001). Traducción y traductología, Introducción a la traductología. Madrid: Cátedra.

JAIMES HERNÁNDEZ, Leslia. (2016). "El Maltrato de Género: Análisis de la película Te doy mis ojos" Espacio Abierto, 25(2): 167-182.

LIFANTE VIDAL, Isabel. (2012). “Amor, dominación y Derecho. Una reflexión a propósito de Te doy mis ojos", InterseXiones, 3: $1-18$.

MARTÍ FERRIOL, J. Luis. (2006). Estudio empírico y descriptivo del método de traducción para doblaje y subtitulación [en línea]. Tesis Doctoral, Universitat Jaume I.

Disponible en:

$<<$ https://www.tdx.cat/handle/10803/10568;jsessionid=63 47D66EB27018FEAD471D70D9188BC1\#page $=166>>$ [Consulta: 10 de mayo de 2019].

MAYORAL ASENCIO, Roberto. (2003). "Procedimientos que persiguen la reducción o expansión del texto en la traducción audiovisual". Sendebar, 14: 107-126.

SOLER PARDO, Betlem. (2013) "Traducción y doblaje: análisis de fuck y su traducción al español en Jackie Brown". EntreCulturas, 6: 127-139.

Fecha de recepción: 2.10.2019 Fecha de aceptación: 20.10.2019

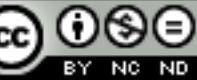


“Transfer” XV: 1-2 (2020), pp. 312-337. ISSN: 1886-554

\title{
Resumen:
}

En una sociedad donde el tema de la violencia de género va tomando cada vez más importancia y visibilidad, el papel del cine como medio de denuncia política y social ha permitido, en la última década, que muchas producciones cinematográficas se hayan dedicado a presentar la temática social relacionada con la violencia hacia la mujer. Este estudio analiza la película Te doy mis ojos, de la directora Icíar Bollaín, desde el ámbito de su traducción para el público italiano, haciendo especial hincapié tanto en los dos guiones, el original y la traducción, como en la puesta en escena. Nos detendremos en los mecanismos narratológicos de la película original y su versión doblada, con el fin de analizar las diferentes formas de percibir los múltiples mensajes verbales violentos que trascienden la pantalla, en el original y en la versión doblada al italiano.

Palabras clave: Traducción audiovisual, Violencia de género, Doblaje, Lenguaje sexista, Cine de mujeres.

\section{AUDIOVISUAL TRANSLATION AND GENDER PERSPECTIVE. ABOUT THE TREATMENT OF VERBAL VIOLENCE IN DUBBING}

\begin{abstract}
:
In a society where the issue of gender violence is becoming increasingly important and visible, in the last decade the role of cinema as a means of political and social protest has allowed that many film productions have dedicated themselves to presenting the social thematic related to violence against women. This paper analyses the film Te doy mis ojos by director Icíar Bollaín, from the scope of its translation for the Italian public, placing special emphasis on both the original and the translation scripts, as well as on the staging. We will focus on the narratological mechanisms of the film, in order to analyse the different ways of perceiving the multiple violent verbal messages that transcend the screen, in both the original and the translated versions.
\end{abstract}


“Transfer” XV: 1-2 (2020), pp. 312-337. ISSN: 1886-554

Keywords: Audiovisual Translation, Gender Violence, Dubbing, Sexist Language, Women's Cinema. 